\title{
ESCRITURA, VERDADE, VIRTUDE
}

\author{
SCRIPTURE, TRUTH, VIRTUE \\ ESCRITURA, VERDAD, VIRTUD
}

\author{
Maria Constança Peres Pissarra \\ Professora Doutora da Pontifícia Universidade Católica de São Paulo \\ mcpp@pucsp.com.br
}

\begin{abstract}
RESUMO: O texto, "Os devaneios de um caminhante solitário" é uma obra póstuma e inacabada, cujo inicio ocorreu em 1776 e a redação continuou até 1778 quando foi interrompida pela morte de seu autor, Jean-Jacques Rousseau. Nos parágrafos iniciais, ele a define como a obra de um homem que não esperava mais nada do mundo, que vivia apenas de suas lembranças e que escrevia tão somente para si mesmo: "Eis-me, portanto, sozinho na terra, tendo apenas a mim mesmo como irmão, próximo, amigo, companhia". [...] Tudo está acabado para mim sobre a terra. [...] Sózinho pelo resto de minha vida, visto que somente em mim encontro a consolaçao, a esperança e a paz, não devo nem quero mais ocupar-me senão comigo mesmo é nesse estado que retomo a continuação do exame severo e sincero que outrora chamei minhas Confissões" (ROUSSEAU, 1995, p. 23 e 26).
\end{abstract}

PALAVRAS-CHAVE: Devaneios de um caminhante solitário. Confissões. Lembranças. Devaneios.

ABSTRACT: The text, Reveries of a Solitary Walker, is a posthumous and unfinished work, which began in 1776 and the writing continued until 1778 when it was interrupted by the death of its author, Jean-Jacques Rousseau. In the opening paragraphs, he defines this work like a man who did not expect anything else in the world, who lived only by his remembrance and who wrote only for himself, "Here I am, therefore, alone on earth, having just myself as a brother, as neighbor, as friend, as companion ". [...] It's all over for me on earth. [...] Alone for the rest of my life, since is only in myself that I find solace, hope and peace, It's my duty and my wish to be concerned entirely with myself, in that state that I return and continued the severe and sincere examination that once I called my Confessions" (ROUSSEAU, 1995, p. 23 e 26).

KEYWORDS: Reveries of a Solitary Walker. Confessions. Remembrance. Reveries.

RESUMEN: El texto "Los devaneos de un caminante solitario" es una obra póstuma e inacabada que se inició en 1776 y cuya redacción continuó hasta 1778 cuando fue interrumpida por la muerte de su autor, Jean-Jacques Rousseau. En los parágrafos iniciales, él a define como la obra de un hombre que no esperaba más nada del mundo, que vivía apenas de sus recuerdos y que escribía unicamente para sí mismo. "Estoy, por lo tanto, solo en la tierra, tengo solamente a mí mismo como hermano, vecino, amigo, compañía" [...] Todo está acabado para mí sobre la tierra [...] Solo por el resto de mi vida, visto que solamente en mí encuentro consuelo, esperanza y paz, no debo ni quiero más ocuparme a no ser conmigo mismo y es en este estado que retomo a continuación del examen severo y sincero que antes llamé mis Confesiones" (ROUSSEAU, 1995, p. 23 e 26).

PALABRAS CLAVE: Devaneos de un caminante solitário. Confesiones. Recuerdos. Rousseau.

${ }^{1}$ Conferência realizada em 08 de abril de 2014 , no $1^{\circ}$ Congresso Nacional Jean-Jacques Rousseau na UFMA em São Luís.

Artigo recebido em setembro de 2015

Aprovado em novembro de 2015

Cad. Pes., São Luís, v. 22, n. Especial, set./dez. 2015 
A virtude da verdade

Desde a premiação do Discurso sobre as ciências e as artes, Rousseau tornara-se uma personagem pública bem conhecida, mas também alvo de críticas. A cada novo embate, aprofundavam-se as diferenças de opinião entre os philosophes de um lado e o pensador genebrino de outro.

Aqueles que antes eram seus amigos, gradativamente, se afastaram e um complô se ergueu contra ele: suas obras foram condenadas e proibidas, nas suas palavras, "o mais sociável e o mais afetuoso dos humanos [...] foi proscrito [da sociedade] por um acordo unânime." Um enredo de acontecimentos - que não se trata aqui de comentar mas apenas de citá-los brevemente - cada vez mais aprofundou aquele conflito: em 1764, Voltaire publicou contra ele um panfleto "anônimo", o Sentiment des citoyens, acusando-o de abandonar seus quatro filhos; no ano seguinte, sua casa em Môtiers, onde se refugiara, foi apedrejada pela população do pequeno vilarejo insuflada pelos sermões do pastor Montmollin. Preocupado com seu amigo, David Hume convidou-o a passarem um tempo juntos, na Inglaterra, enquanto os ânimos se acalmavam. Em vão: apenas um ano e meio depois, ele partia após romper com o filósofo inglês. Ao voltar para a França, entende que precisa justificar-se a todos e decide fazer leituras públicas das Confissões, que começara a escrever na sua temporada inglesa, o que despertou a ira de uma dama da sociedade, pertencente ao seu antigo grupo de amigos, Mme. D’ Epinay, que se sentiu ameaçada por antecipação.

Impedido de provar sua inocência, Rousseau redigiu outro texto com essa mesma intenção, os Dialogos ou Rousseau juiz de Jean-Jacques, e decidiu depositar o manuscrito no altar da lgreja Notre Dame de Paris, pois, se não mais podia esperar o julgamento dos homens, buscava o de Deus, como já anunciara na página inicial das Confissões:

Que a trombeta do julgamento final soe quando ela quiser; eu virei com esse livro na mão me apresentar frente ao soberano juiz. Direi altivo: Eis o que fiz, o que pensei, o que fui. Disse o bem e o mal com a mesma franqueza. Nada calei de mau, nada acrescentei de bom; e se me aconteceu usar algum ornato indiferente, não foi nunca para preencher um vácuo da minha falta de memória. Talvez tenha imaginado ser verdadeiro o que eu acreditava que o devesse ser, porém jamais o que eu soubesse ser falso. (ROUSSEAU, 1959, p. 30).

A grade do altar fechada pareceu-lhe um sinal do céu. Decidiu, então, escrever e distribuir pelas ruas de Paris sua mensagem intitulada $A$ tout français aimant la justice et la vérité. Insatisfeito com a compreensão de seus contemporâneos, começa poucos meses depois, no outono de 1776, a redação dos Devaneios, que o ocuparão até o final de sua vida em 1778, mas só serão publlicados quatro anos depois de sua morte.

Esse breve resumo teve apenas a intenção de situar os Devaneios, um dos textos autobiográficos de Rousseau, no plano geral de sua obra. Certamente, nestes dias dedicados aos Devaneios, aprofundaremos o sentido desse livro, portanto vou apenas levantar algumas questões que mais adiante me ajudarão a justificar minha escolha para esta nossa conversa, hoje, da $4^{a}$ caminhada.

A ligação entre essas obras está registrada já na Primeira Caminhada: "estas páginas podem, então, ser vistas como um apêndice de minhas Confissões” (RAYMOND, 1962, p. 14). Mas, os Devaneios não são a continuação dos Diálogos como sequência linear. Ali, em uma desordem apenas aparente, as lembranças, as confidências, as reflexões constituem o ponto essencial. Os Devaneios não são o simples retrato das recordações trazidas à luz pela memória, mas a tentativa derradeira de encontrar um sentido para a vida a partir do exame de consciência de um homem sincero - Jean-Jacques Rousseau. 
A coerência interna desse texto autobiográfico está no "eu" que percorre toda a obra, como que organizando a desordem provocada pela imaginação, pelas lembranças desse eu. A linguagem em que é expresso está marcada por hesitações; por meio dela, falam diferentes vozes, não como vozes dissonantes, mas que se entrelaçam, como a estabelecer uma relação entre o pensamento, a escrita e a vida.

No início da Segunda Caminhada, Rousseau (1959, p. 1002) assim se refere ao seu propósito:

Tendo, então, concebido o projeto de descrever o estado habitual de minha alma na mais estranha condição na qual se pode encontrar um mortal, não vi maneira mais simples e mais segura de executar essa empreitada do que fazer um registro fiel de minhas caminhadas solitárias e dos devaneios que as preenchem, quando deixo minha cabeça inteiramente livre e minhas ideias seguem sua direção sem resistência e sem preocupação. Essas horas de solidão e de meditação são as únicas do dia nas quais sou plenamente eu mesmo, comigo mesmo, sem diversão, sem obstáculo e quando posso verdadeiramente dizer aquilo que a natureza quis.

Ao longo de suas caminhadas solitárias, deixa seu pensamento vagar inteiramente livre, guiado tão somente pela sua imaginação, respondendo, assim, à determinação da natureza.

Decide-se, então, circunscrever-se a si mesmo, a escrever apenas para si, pois "passando a minha vida comigo, devo conhecer-me" (ROUSSEAU, 1964, p. 968), lembrava Rousseau no Prefácio de Narciso. O objetivo dos Devaneios é viver nele mesmo, é ter apenas a si como leitor, deixando seu espírito vagar, sem a preocupação de convencer ou demonstrar seus pensamentos aos outros, ou melhor, ao partido dos filósofos.

Se a reunião no mesmo título das palavras rêverie (devaneio) e promenade (caminhada), pode intrigar o leitor desavisado ao reunir palavras de significados opostos, trata-se de mais um paradoxo entre tantos recorrentes nos textos de Rousseau: ao se referir ao ato de pensar, ele ressalta a presença do corpo como fundamental. O homem não é puro pensamento, o cogito cartesiano é substituído por um corpo vivo que pensa e que se sente vivo, ou seja, "é ao sentimento de existência, à maneira singular de experimentar cada vez, na afetividade de sua carne, que o homem deve a revelaçao de seu eu" (AUDI, 2010, p. 50). As viagens feitas a pé e sozinho sempre o motivaram, a caminhada tem qualquer coisa que anima e aviva, enfatiza Rousseau (1995, p. 31) no começo da Segunda Caminhada:

Não vi maneira mais simples e mais segura de executar essa empresa do que a de manter um registro fiel de minhas caminhadas solitárias e dos devaneios que as preenchem, quando deixo minha cabeça inteiramente livre e minhas idéias seguirem sua inclinação, sem resistência e sem embaraços. Essas horas de solidão e meditação são as únicas do dia em que sou plenamente eu mesmo e em que me pertenço sem distração, sem obstáculos e em que posso verdadeiramente dizer que sou o que desejou a natureza.

A imaginação e os devaneios são estimulados pela caminhada. A natureza nunca mente, em oposição "à autoridade dos homens que são mentirosos" (ROUSSEAU, 1995, p. 109).

As caminhadas pelo campo, a herborização, levam-no a lugares solitários, próprios aos devaneios, pois esse era um prazer que os homens não poderiam tirar-lhe; a caminhada representa aquele que não mais está submetido a nenhum percurso previamente estabelecido, que não mais está preso às contigências sociais. Deixar-se andar em meio à natureza para melhor ouvir a crítica que ela permite fazer à sociedade e ao progresso fundados na desigualdade em um tempo que não é o cronológico, em um tempo que não é o dos fatos comuns "ordenados no tempo, dispostos em sequência como numa fila", nas palavras de Bruno Schulz em seu excepcional livro Sanatório. Mas indaga ainda Bruno Schulz (1994, p. 32): 


\begin{abstract}
O que fazer com os acontecimentos que não tem seu próprio lugar no tempo, os acontecimentos que chegaram tarde demais, quando o tempo já foi distribuído, dividido, desmontado, e que agora ficaram numa fria, não alinhados, suspensos no ar, sem lar, errantes? Será que o tempo não é estreito demais para abrigar todos os acontecimentos?
\end{abstract}

Há dois tempos paralelos tal qual os trilhos, postos um ao lado dos outros; sobre estes o trem se desloca, mas, ao longo da ferrovia, outros deslocamentos acontecem sobre "braços laterais".

Os fatos comuns, cotidianos, e históricos, sucedem-se cronologicamente, alinhados um após o outro, sendo, portanto, eventos. Já os acontecimentos "extranumerários", para usar uma expressão de Schulz, não podem ser agrupados, arranjados, entre antecedentes e consequências. Seguem o registro contraditório da memória. Rousseau reinventa, modifica os registros do tempo, percorre todos os eventos de sua existência já passada, reconstruindo, assim, seu passado no presente, é necessário mergulhar no tempo para dizer sua vitória sobre o tempo. O tempo da felicidade é um breve parêntese; ele não é feito para o homem "que vive entre os eventos, ele está perdido para sempre e apenas existe para a memória nostálgica" (SCHULZ, 1994, p. 143). E é evocado pelos devaneios de um caminhante solitário junto à natureza. O plano dos Devaneios é psicológico, os sentimentos e as ideias são agrupados por afinidade e não por uma linearidade temporal. O sentimento da existência não é resultado da meditação, e sim do devaneio. A ordem das razões é substituída pela ordem dos sentimentos no quadro da vida.

Entre as dez caminhadas que compõem o texto, a quarta destaca-se por apresentar ao leitor um exame de consciência e uma reflexão filosófica sobre a mentira, a partir da indagação de Rousseau de suas experiências sobre a verdade e a mentira, ao mesmo tempo que se questiona se foi sempre fiel à sua divisa: vitam impedere vero. A maioria dos devaneios são meditações morais e filosóficas, mas que começam em geral com algum pretexto.

Com a quarta caminhada não é diferente ao se referir a Plutarco - "anteontem, lia em suas obras morais o tratado O proveito que se pode tirar dos inimigos" - e à casual descoberta de um artigo do Padre Rosier - "no mesmo dia, pondo em ordem algumas brochuras que me foram enviadas por seus autores, encontrei um dos jornais do Padre Rosier". Esses pretextos deram-Ihe o tema da caminhada: "Para por em prática as lições do bom Plutarco, resolvi usar a caminhada do dia seguinte para me examinar sobre a mentira" (ROUSSEAU, 1995, p. 55). Mas, é importante acrescentar, Rousseau sentiu-se provocado pela frase escrita pelo religioso no exemplar que lhe enviara: "vitam vero independenti, Rosier - àquele que dedica sua vida à verdade, Rosier". Desde o Primeiro Discurso, Rousseau declarava defender "o partido da verdade", tema por ele retomado no Prefácio de Narciso. Em outro texto, na Carta d'Alembert, Rousseau - inspirado em Juvenal (Juvenal. Sátiras, IV, 9.) - tinha escolhido como sua divisa "vitam impedere vero - a vida em nome da verdade", frase também retomada nas Cartas escritas da montanha.

O próprio Rousseau refere-se ao texto da Quarta Caminhada como "discussões embaraçosas" que apresenta um movimento sinuoso, nem sempre muito fácil de seguir e está dividido em três partes (ROUSSEAU, 1995, p. 55).

\title{
Parte 1: §§ 1-5: um prelúdio/introdução - $1^{\circ}$ exame de consciência
}

A primeira parte é constituída pelos cinco primeiros parágrafos, uma espécie de introdução à caminhada, que começa pela referência aos dois textos que o incentivaram a refletir sobre a mentira. O título do livro de Plutarco - seu autor favorito - é revelador por si só: Como tirar proveito de seus inimigos. A partir dele, Rousseau (1995) vai tentar tirar proveito da frase escrita de forma provocativa no jornal, pois, segundo ele, "por demais acostumado aos giros desses Senhores para enganar-me com esse, compreendi que ele pensara, com esse ar de polidez, dizer-me uma cruel antífrase". 
Imbuído dessa intenção, relata ele:

No dia seguinte, tendo-me posto a caminho para executar essa resolução, a primeira idéia que tive, ao iniciar meu recolhimento, foi a de uma mentira horrível, dita na primeira juventude,cuja lembrança me perturbou por toda a vida, e vem até na minha velhice, contristar ainda meu coração já dilacerado de tantas outras maneiras. (ROUSSEAU, 1995, p. 55).

Ora, refletir sobre a mentira é refletir sobre sua experiência da verdade e da mentira, o que significa indagar-se se foi fiel à sua divisa, como também à intenção claramente afirmada no início das Confissões: "quero mostrar aos meus semelhantes um homem em toda a verdade da natureza; e serei eu esse homem" (ROUSSEAU, 1959, p. 29).

Mas precisará acrescentar outra pergunta àquela - como lhe foi fiel? - pois dois parágrafos abaixo afirma que "Talvez tenha imaginado ser verdadeiro o que [...] acreditava que o devesse ser, porém jamais o que [...] soubesse ser falso" (ROUSSEAU, 1959, p. 29). Afirmação que é desmentida nas próprias Confissões, algumas páginas à frente, ao final do livrro II. Rousseau ali relata que, quando era lacaio na casa da Sra Vercellis, acusou Marion, a cozinheira, do roubo de uma fita, sendo que ele era o autor do roubo. Recorda ele:

\begin{abstract}
Muitas outras coisas melhores estavam ao meu alcance. E apenas essa fita me tentou, roubei-a, e como eu quase não a escondia, depressa a acharam. Procuraram saber onde a achara. Perturbei-me, balbuciei, e disse, afinal, corando, que fora Marion que ma dera. [...] Marion não só era bonita, [...] e além disso, boa rapariga, séria, de uma fidelidade a toda prova. [...] chamaram-na [...] Ela chegou e mostraram-Ihe a fita. Culpei-a cinicamente. Ela ficou interdita, calou-se, lançou-me um olhar que teria desarmado os demônios, e ao qual o meu bárbaro coração resistiu. (ROUSSEAU, 1959, p. 29 e 97-98).
\end{abstract}

E é exatamente esse episódio que lhe vem à lembrança, quando do exame de consciência provocado por aqueles dois acontecimentos relatados no início da $4^{a}$ Caminhada. Ainda adolescente, Rousseau deixou condenar no seu lugar uma jovem inocente e vulnerável, mas, dizia ele:

Consultando apenas minha disposição ao dizê-la, essa mentira não foi mais do que um fruto da falsa vergonha, e, longe de ter tido a intenção de prejudicar aquela que foi vítima, posso jurar perante e céu que no próprio instante em que essa vergonha invencível ma arrancava, teria dado com alegria todo o meu sangue para fazer cair suas consequências apenas sobre mim. (ROUSSEAU, 1995, p. 55).

Rousseau nos explica, então, que havia atenuantes para sua ação, pois ele não tivera a intenção de prejudicar a jovem Marion, não havia maldade na sua ação. Mas não teria sido esse desvio na juventude que o levou a adotar sua divisa vitam impedere vero? Não lhe parecia, pois mesmo essa atitude inexplicável não foi capaz de evitar que ele praticasse outras mentiras, sem necessidade ou remorso. Ao voltar o olhar para si mesmo, lembrava-se de várias coisas inventadas que disse como verdadeiras, muito embora - continua ele na $4^{a}$ caminhada - "intimamente orgulhoso de meu amor pela verdade, sacrificava-Ihe minha segurança, meus interesses, minha pessoa, com uma imparcialidade de que não conheço nenhum outro exemplo entre os humanos" (ROUSSEAU, 1995, p. 56).

Essa primeira parte da caminhada traz um problema moral concernante apenas a Rousseau; refletir sobre ele, na sequência, será refletir sobre a mentira da perspectiva da filosofia moral, mas sem esquecer sua experiência pessoal, aparentemente contraditória, pois pensar sobre sua conduta é pensar como se conduzir. 


\title{
Parte 2: §§ 6-24: dissertação de filosofia moral sobre a mentira
}

A segunda parte inicia-se com uma lembrança que the ocorre de uma frase lida em um livro de Filosofia: "mentir é esconder uma verdade que deve ser manifestada" (ROUSSEAU, 1995, p. 56). Essa frase significa, de um lado, indagar-se "quando e como se deve a outrem a verdade" e, de outro, se é possível "enganar inocentemente". A resposta a essa indagação, orientada pelo método dedutivo, permite-lhe concluir que "não dizer o que é verdadeiro e dizer o que é falso são duas coisas muito diferentes, mas de que pode, contudo, resultar o mesmo efeito; pois esse resultado é ceretamente o mesmo em todas as vezes que esse efeito é inexistente" (ROUSSEAU, 1995, p. 57).

Mas "questões assim sumariamente resolvidas" não podem fornecer "alguma explicação segura para a prática", pois como julgar quando posso mentir? "Se a obrigação de dizer a verdade não está baseada senão em sua utilidade, como poderia constituir-me juiz dessa utilidade?" (ROUSSEAU, 1995). Talvez se possa tirar daí uma primeira conclusão: se não resulta nenhum mal da minha mentira, se não engano a outrem, também não faço o mal a mim mesmo. Logo:

Quantas discussões embaraçosas seriam fáceis de evitar se disséssemos a nós mesmo, sejamos sempre sinceros mesmo correndo todos os riscos. A própria justiça está na verdade das coisas; a mentira é sempre iniquidade, o erro é sempre impostura quando apresentamos o que não é. (ROUSSEAU, 1995, p. 58).

Ao afirmar esse supremo paradoxo - o mentiroso, eventualmente, pode ser inocente -, Rousseau (1995, p. 58) apresenta uma segunda conclusão apoiada na intenção da mentira:

\begin{abstract}
Pois não se tratava de julgar se seria bom dizermos sempre a verdade mas se éramos sempre igualmente obrigados a fazê-lo, e, quanto à definição que examinava, supondo que não o fosse, tratava-se de distinguir os casos em que a verdade é rigorosamente devida, daqueles em que se pode calar sem injustiça e mascará-la sem mentira: pois descobrir que tais casos existem realmente.
\end{abstract}

A culpa está na intenção da ação e não no agente moral.

E, como não é fácil passar do princípio moral à sua aplicação, pergunta-se "de onde extrair essa regra e a prova de sua infalibilidade?" Sua resposta é clara: a consciência é um guia melhor do que a razão: "em todas as questões de moral difíceis como esta, sempre consegui resolvê-las antes pelo ditame de minha consciência que pelas luzes de minha razão. $O$ instinto moral nunca me enganou" (ROUSSEAU, 1995, p. 58).

Além disso, tanto quanto a intenção é possível julgar a consequência de qualquer um de nossos atos? Não, pois "para tornar uma mentira inofensiva, não basta que a intenção de prejudicar não esteja expressa, é necessária, além disso, a certeza de que o erro no qual são lançados aqueles a quem se fala, não possa prejudicar, de uma maneira ou de outra, nem a eles nem a ninguém" (ROUSSEAU, 1995, p. 59). Não basta ter certeza sobre a intenção, dificlmente se pode prever a consequência de um ato, mesmo que possa haver mentiras inocentes. Para dar mais clareza à sua afirmação, estabelece uma relação entre a vantagem que se venha a ter ou não, e a mentira enunciada, estabelecendo quatro tipos diferentes de mentira: "mentir em vantagem própria é impostura, mentir em vantagem alheia é fraude, mentir para prejudicar é calúnia. [...] [Já] Mentir sem prejuízo para si nem para outrem, não é mentir: não é mentira, é ficção" (ROUSSEAU, 1995, p. 59).

Afirmação polêmica e de extraordinária oratória: não há mentira nos fatos inventados, como nas fábulas, mas sim na falsa polidez dos homens da sociedade corrompida, "pois dizer uma coisa em vantagem própria não é mentir menos do que dizê-la em prejuízo de outrem, embora a mentira seja menos criminosa. [...] Eis o limite exato: mas tudo o que, sendo contrário à verdade, não interessa de nenhuma maneira à justiça, é apenas ficção [...]" (ROUSSEAU, 1995, p. 60). 
De um ser imaginário tudo pode ser dito, mas não de pessoas reais, seja para meu proveito ou para ou de outrem, ambas são mentiras injustas, são "oficiosas", diz Rousseau. Mais ainda, é "esse tipo de pessoas que em sociedade são chamadas sinceras" (ROUSSEAU, 1995, p. 60). Mas em que consiste sua sinceridade? Nas afirmações banais do cotidiano, nas referências pontuais, no portar-se adequadamente em sociedade de acordo com o papel que lhe está atribuído.

A esse homem do mundo, das sociedades degeneradas, Rousseau opõe o homem da natureza, ao mesmo tempo em que aponta as diferenças morais entre eles:

\begin{abstract}
O homem a que chamo sincero faz exatamente o contrário. [...] ele é solidamente sincero mesmo contra seu interesse ainda que pouco lhe interesse sê-lo nas conversas sem importância. Ele é sincero porque não procura enganar ninguém, porque é tão fiel à verdade que $o$ acusa quanto àquela que o honra e porque nunca engana em vantagem própria nem para prejudicar seu inimigo. A diferença, portanto, que há entre meu homem sincero e o outro é que o homem da sociedade é rigorosamente fiel a toda a verdade que não the custa nada , mas não vai além enquanto o meu nunca a serve tão fielmente como quando é preciso imolar-se por ela. (ROUSSEAU, 1995, p. 61).
\end{abstract}

Parte 3: §§ 25-39: examina de forma crítica as mentiras de sua vida, principalmente a partir da redação das Confissões.

$\mathrm{Na}$ terceira parte desse percurso, fecha-se o movimento da caminhada ao retomar o exame de consciência já anunciado nos primeiros parágrafos. Ali já afirmou que as únicas regras morais às quais obedeceu foram as intuições morais nascidas dos seus impulsos. Não conseguiu evitar as mentiras veniais, como o roubo da fita de que acusou Marion, mas pelo menos evitou as mentiras premeditadas, evitou o interesse pessoal, principio intencional da má ação, como esclarece ao afirmar: "não minto nem por interesse nem por amor próprio, ainda menos por inveja ou por malignidade: mas unicamente por acanhamento e falsa vergonha" (ROUSSEAU, 1995, p. 63). Um último exemplo mais uma vez confirma essa afirmação: durante um almoço com outras pessoas, uma jovem grávida, para provocá-lo, perguntou-lhe se tinha filhos. A resposta imediata foi afirmar que não tivera essa felicidade. Mas, por que não respondera de forma a embaraçá-la por fazer tal pergunta a um homem que envelhecera solteiro? Por que não constranger aos que queriam vê-lo constrangido, por que mentir? Por embaraço, por timidez, responde Rousseau (1995, p. 63), não de forma premeditada para enganar: "nunca senti melhor minha aversão natural pela mentira do que ao escrever minhas confissões."

A questão principal não é dizer aquilo que se define como verdade ou como mentira, e sim, seguir as direções morais de sua consciência, pois pode-se fantasiar à vontade, mas não se pode mentir, pois a verdade é uma virtude, "em qualquer outro sentido ela não é para nós senão um ser metafísico, de que não resulta nem bem nem mal” (ROUSSEAU, 1995, p. 66).

\title{
Conclusão: §§ 40-42: escritura mais fina, espécie de nota final
}

O caminho tortuoso percorrido pela Quarta Caminhada mostra a importância que nela tem o problema moral. Rousseau descobre que ele se satisfaz frequentemente com falsos atalhos e tende a fabricar álibis [...] ao mesmo tempo, o movimento sinuoso do texto deixa transparecer um progresso do pensamento: este se dirige por meio de um exame de consciência e a reflexão abstrata em direção daquilo que é vital para Rousseau: a defesa de sua obra. A defesa do Eu comporta, como momento essencial, a da obra posto que é o personagem Jean-Jacques Rousseau que está no centro da polêmica imposta pelo adversário. A obra não pode se separar da base existencial e as Confissões são a peça essencial desse dossie. (MARIE, 1998, p. 75-76). 
A caminhada não é uma fonte de inspiração na qual a meditação se alimente, pelo contrário, o espírito se fecha ao espetáculo exterior em um movimento de ascese do pensamento.

Em seu texto O livro por vir, Maurice Blanchot afirma, referindo-se a Rousseau, que sempre suspeitou:

Do vício profundo e inatingível de considerá-lo como aquele a quem devemos a literatura. Rousseau, o homem do começo, da natureza, da verdade, é aquele que só pode efetuar essas relações escrevendo; escrevendo, só pode fazê-las desviar da certeza que tem delas; nesse desvio de que sofre, que recusa com ímpeto e desespero, ajuda a literatura a tomar consciência dela mesma, desligando-se das convenções antigas, e a formar, na contestação e nas contradições, uma nova retidão. (BLANCHOT, 2013, p. 57-58).

Sagrada, a vocação literária, ao mesmo tempo é um mal, pois aquele que escreve entra na mentira e na vaidade da literatura. Mas, escrever também é entrar em um mundo novo, é estabelecer outra relação de entusiasmo "com a verdade, a liberdade e a virtude" (BLANCHOT, 2013, p. 59). Mas isso "é ainda se perder, já que, tornado outro, diferente do que era - outro homem, em outro universo -, ei-lo doravante infiel à sua verdadeira natureza [...] e obrigado a empenhar-se numa busca que, no entanto, não tem outro objeto a não ser ele mesmo" (BLANCHOT, 2013, p. 59).

Obstinado pela escrita, Rousseau escreve contra a escrita, mergulha na literatura na expectativa de sair dela, mas não consegue e não pode parar de escrever, pois a escrita tornou-se sua única possibilidade de comunicação. Como lembra Blanchot (2013, p. 59):

Usar a mentira literária para denunciar a mentira social é, de fato, um antiquíssimo privilégio herdado dos céticos e dos cínicos. Mas Rousseau, ao tomar de empréstimo aos Antigos uma tradição que conhece, não deixa de pressentir que, com ele e pelo desafio solitário a que ela o destina, a literatura vai empreender uma nova aventura e revelar estranhos poderes.

O "exilio" no acolhimento da natureza em oposição à barbárie da civilização não foi apenas uma imposição das circunstâncias, ao contrário, foi também uma decisão. Distanciar-se é a forma de explicar aos seus contemporâneos que o distanciamento é uma escolha pedagógica, que o distanciamento de Paris é mais do que o mero rompimento com o que representava aquela cidade: era distanciar-se para melhor conhecer-se, para lembrar e escrever. Se furtar aos olhares dos outros era esconder-se, era revelar-se não para o mundo ou para seus contemporâneos, mas para si mesmo, era voltar o olhar para si e ali buscar ouvir a sua voz.

O tom de certo maneira magistral, do início dos Devaneios, é revelador:

Eis-me, aqui, sozinho sobre a terra, não tendo mais irmão, nem alguém próximo, nem amigo, nem outra companhia que não seja a minha. O mais sociável e o mais amoroso dos humanos foi proscrito por um acordo unanime. Procuraram no refinamento de sua raiva que agressão poderia ser a mais cruel à minha alma sensível, quebrando violentamente todos os laços que me prendiam a eles. Eu teria amado os homens apesar deles mesmos [...] Mas, eí-los estranhos, desconhecidos, enfim nulos para mim, posto que assim o quiseram. Mas eu, afastado deles e de tudo, o que sou eu mesmo? Eis o que me resta procurar. (ROUSSEAU, 1995, p. 7).

Esse parágrafo abre-se com uma afirmação sobre o eu que ao mesmo tempo surpreende o leitor, pois anuncia também uma conclusão: a bondade de Jean-Jacques e a maldade dos homens. Só este recurso à subjetividade pode levá-lo à verdade para finalmente poder legá-la à posteridade. Como consequência do complô que contra ele se estabeleleceu, encontra-se sozinho. 
Apenas em si mesmo poderá buscar "a consolação, a esperança e a paz" e, como resultado da reflexão sobre suas disposições de alma, "conseguir melhor ordená-las e corrigir o mal que nelas ainda possa restar". E acrescenta:

\begin{abstract}
Minhas meditações não serão inteiramente inúteis e mesmo que eu não sirva para nada sobre a terra, não terei, absolutamente perdido meus últimos dias. As alegrias de minhas caminhadas diárias foram com frequência preenchidas por contemplações charmosas, das quais lamento ter perdido a lembrança. Fixarei por meio da escrita aquelas das quais ainda puder me lembrar [...]. (ROUSSEAU, 1995, p. 13-14).
\end{abstract}

Só a escritura pode registrar essa viagem. Mas não se trata da viagem de alguém interessado em conhecer novos lugares. Ao contrário, sua viagem está muito próxima, é a si mesmo que Rousseau pretende conhecer, sua viagem é interior, introspectiva. A escritura significa, nos Devaneios, o lugar da simbologia de um novo reconhecimento das fronteiras do eu²; suas lembranças pessoais são a possibilidade de uma filosofia da felicidade. Inaugura, assim, a filosofia do sentimento ou, segundo Jean Wahl (1962), renova o sentimento da existência.

Em oposição ao pensamento iluminista, sonhar, meditar, imaginar representam a verdadeira liberdade, satisfaz-se com a pura percepção sensível, sente-se em harmonia com os elementos naturais. Mais tarde, encontraremos em Proust o eco dessa superioridade do devaneio sobre o pensamento: "é melhor sonhar sua vida do que vivê-la", dirá ele.

De acordo com Jean Starobinski (2011), é na escrita autobiográfica que a procura da transparência atinge seu fim, ou seja, seu exilio representaria mais do que distanciar-se como um misantropo, um mergulhar em si mesmo para tirar a máscara que lhe encobria o rosto, ao mesmo tempo em que se abre a alteridade, como afirma Blaise Bachofen. Para ela, a introspecção representa a condição fundamental da atenção aos outros:

Si Rousseau fait de la méditation le fondement de sa réflexion anthropologique, c'est que la connaissance de l'homme ne peut prendre la forme d'un savoir de savant ou de raisonneur, d'une philosophie étrangère au philosophe qui en est le sujet. Toute recherche sur l'homme est une recherche sur soi, qui ne peut relever des méthodes habituelles de la recherche empirique. (BACHOFEN, 2002, p. 58).

\footnotetext{
${ }^{2}$ Questão fundamental nas obras autobiográficas de Rousseau é o outro da escritura, aquele a quem ela se dirige, mas que não é o tema de nossa conversa hoje.
} 
ESCRITURA, VERDADE, VIRTUDE | Maria Constança Peres Pissarra

\section{Referências}

AUDI, P. Marcher et rever. Le nouvel observateur: le génie de la modernité, n. 76, p. 50-52, juil./août 2010. Hor-série.

BACHOFEN, B. La codition de la liberte. Paris: Payot, 2002.

BLANCHOT, M. O livro por vir. São Paulo: Martins Fontes, 2013.

BURGELIN, P. La philosophie de l'existence de J.J. Rousseau. Paris: Vrin, 1973.

CORBIN, S. Heurs et malheurs du don dans l'œuvre de Jean-Jacques Rousseau. CONTEXTES, n. 5, maio 2009. Disponível em: <http://contextes.revues.org/4271 ; DOI : 10.4000/contextes.4271>. Acesso em: 26 jan 2014.

MARIE, D. Les reveries du promeneur solitaire. Paris: Bertrand Lacoste; Parcours de Lecture, 1998.
RAYMOND, M. Jean-Jacques Rousseau, la quête de soi et la rêverie. Paris: José Corti, 1962.

ROUSSEAU, J.-J. Oeuvres complètes. Paris: Gallimard, 1959-1995. (Bibliothèque de la Pléiade).

. Os devaneios de um caminhante solitário. 3. èd. Brasília: UnB; Hucitec, 1995.

SCHULZ, B. Sanatório. Rio de Janeiro: Imago Editora, 1994.

STAROBINSKI, J. A transparência e o obstáculo. São Paulo: Cia. das Letras, 2011.

Jean-Jacques Rousseau: la transparence et l'obstacle. Paris: Plon, 1957 ; réédition, Gallimard, 1976.

WAHL, J. Tableau de la philosophie frnaçaise. Paris: Gallimard, 1962. 